\title{
Techniques Employed in the Physicochemical Characterization of Activated Carbons
}

\author{
Carlos J. Durán-Valle \\ Universidad de Extremadura \\ Spain
}

\section{Introduction}

Activated carbons have been widely used as adsorbents, catalyst supports, catalysts, and electronic materials due to its properties: high surface area, large pore volume, and chemical-modifiable surface (Do, 1998). These properties determine its application.

Porous solids are materials full of pores; when the main type of pore is microporous, these materials have large internal surfaces. This property is of great importance in adsorption, and its study is essential in the characterization of activated carbons. Pore structure and specific surface can be controlled by several factors: carbonization atmosphere, activation agent, precursor, time and temperature of thermal treatment, the use of templates to synthesize the precursor, particle size, and chemical treatment. The same factors, but with different intensity, control the functional groups in the surface. Also, the functional groups in activated carbons were found to be responsible for the variety in physical and chemical properties (Bandosz, 2009). So, a great amount research has focused on how to modify and characterize the surface functional groups of activated carbons in order to improve their applications or understand their properties (Calvino-Casilda et al., 2010; Moreno-Castilla, 2004; Shen et al., 2008). In the last decades, a large number of techniques have been developed to study various surface properties in solids (Somorjai, 1994). The frontiers of instrumentation are constantly being pushed toward better conditions: finer detail (spatial resolution, energy resolution, and composition accuracy), better sensibility, automation, and cheaper equipment. Activated carbon presents some peculiarities: it is a non-crystalline material (amorphous), is a non-stoichiometric solid with variable composition, and it is opaque to most wavelengths and species used in a characterization laboratory. The chemistry of carbon is extremely complex (Schlogl, 1997; Do, 1998); the main reason for this complexity lies in the pronounced tendency of this element to form homonuclear bonds in three bonding geometries $\left(s p, s p^{2}\right.$, and $\left.s p^{3}\right)$ and in the moderate electronegativity of carbon, which allows strong covalent interactions with other elements. Because of the use of only one technique does not provide all the necessary information about surfaces, the tendency is to use a combination of techniques. In this chapter, some of the more common techniques used in the characterization of activated carbons are shown. 


\section{Density measurements and pore volume}

There are several "densities" related with activated carbons. These can be mentioned as:

- bulk density, which can be defined as the volume of a full recipient that contains a determined mass of activated carbon. This volume includes: a) activated carbon's atoms; b) pores; and c) space between particles.

- mercury density, where this liquid is used to refill the space between particles, but its high surface tension maintains $\mathrm{Hg}$ out of pores.

- true density or helium density, Helium, as gas with small size molecules, can go into pores (really, only accessible to pores according to the molecular size of helium). The helium density gives a measure of the density of the carbon structure.

The total volume of pores can be calculated from $\mathrm{Hg}$ and He densities by:

$$
V=\frac{1}{\rho_{H e}}-\frac{1}{\rho_{H g}}
$$

where $V$ is the pore volume, $\rho_{\mathrm{He}}$ is the He density, and $\rho_{\mathrm{Hg}}$ is $\mathrm{Hg}$ density, respectively.

In preparation of charcoal, these values have been studied for different temperatures and times of preparation of charcoal (Durán-Valle et al., 2006; Pastor-Villegas \& Durán-Valle, 2002).

\section{Porosimetry}

The pores of solids are of different kinds. The individual pores may vary in size and in shape. With respect to the shape, in activated carbons, the predominant type is the slit-shape pore. But, the width of the pores is also of special interest for many purposes. A classification of pores according to their average width, which was adopted by the IUPAC (IUPAC, 1972; Sing et al., 1985) is shown in Table 1.

In recent years, the micropore range has been subdivided into very narrow pores (until 0.8 $\mathrm{nm}$ ) or ultramicropores, where the enhancement of interaction potential is caused by the similarity in size between the pore and molecules, and supermicropores, which have a width $(0.8$ to $2.0 \mathrm{~nm})$ between ultramicropores and mesopores (Gregg \& Sing, 1982). Carbon-based materials usually have a bimodal pore size distribution, with one dominant peak being less than approximately $2 \mathrm{~nm}$ and the other major peak usually greater than 50 nm (Do et al., 2008).

The volume of macropores it is usually on the order of $0.2-0.5 \mathrm{~cm}^{3} \mathrm{~g}-1$, but the associated area is very small, on the order of $0.5 \mathrm{~m}^{2} \mathrm{~g}^{-1}$, which is negligible in an activated carbon (Do, 1998). Macropores are not important for the adsorption capacity, but their importance is because they act as transport pores to the meso- and micropores. Mesopores have a volume in the 
range of 0.1 to $0.4 \mathrm{~cm}^{3} \mathrm{~g}^{-1}$, and the surface area is in the range of $10-100 \mathrm{~m}^{2} \mathrm{~g}-1$. Their contribution to adsorption is significant, and they act as transport to micropores. Micropores have a similar volume, but the surface area is the most important, sometimes near to 1000 $\mathrm{m}^{2} \mathrm{~g}^{-1}$.

\begin{tabular}{|l|l|}
\hline Type & Width $(\mathrm{nm})$ \\
\hline Micropores & $<2$ \\
\hline Mesopores & $>2$ and $<50$ \\
\hline Macropores & $>50$ \\
\hline
\end{tabular}

Table 1. IUPAC classification of pores according to their width.

The characterization of porous activated carbon and its derivatives has been a subject of great interest for many decades. Two main experimental tools are used for this study: mercury porosimetry and gas adsorption.

Mercury porosimetry is a technique that was originally developed to determine pore sizes in the macropore range, where the gas adsorption is not adequate (Gregg \& Sing, 1982). Since the contact angle of mercury with solids is $>90^{\circ}$, an excess pressure $p$ is required to force the liquid mercury into a pore of radius $r$. Washburn (1921) suggested the following basic equation:

$$
r=\frac{2 \gamma \cos \theta}{p}
$$

where $\gamma$ is the surface tension of mercury $\left(484 \mathrm{mN} \mathrm{m}^{-1}\right)$ and $\theta$ is the contact angle $\left(141^{\circ}\right)$ recommended by IUPAC (Sing et al, 1985).

The technique of mercury porosimetry consists of measuring the extent of mercury penetration into the pores of a solid as a function of the applied pressure. Automatic porosimeters are now in use for the routine examination of pore structures for catalysts, adsorbents, cements, refractory materials, and other materials. The measure range of porosimeters application extends from macropores to near of the limit between micropores and mesopores. Thus, there is an overlap with the gas adsorption method in the mesopore range.

\section{Gas adsorption}

The ability to adsorb and desorb gases from the coals has been known for a long time (Scheele, 1780). A large amount of the information about the physical structure of a surface (i.e., specific surface and pores) comes from the amount of gas adsorbed on this surface as a function of gas pressure at a given temperature. Mercury porosimetry and gas adsorption are complementary techniques: porosimetry can measure mesopores and macropores, and gas adsorption measures micropores and mesopores.

The curves derived from these experiments are called adsorption isotherms. They can be used to determine thermodynamic parameters (e.g., heat of adsorption), the pore distribution, and 
the surface area. The IUPAC recommends a classification based on six types of isotherms these are shown in Figure 1. Types I to V were proposed by Brunauer, Deming, Deming, and Teller (Brunauer et al., 1940) and they are referred to as BDDT. Type VI was subsequently added (Gregg \& Sing, 1982). There are a considerable number of borderline cases that are difficult to assign to one group rather than another.
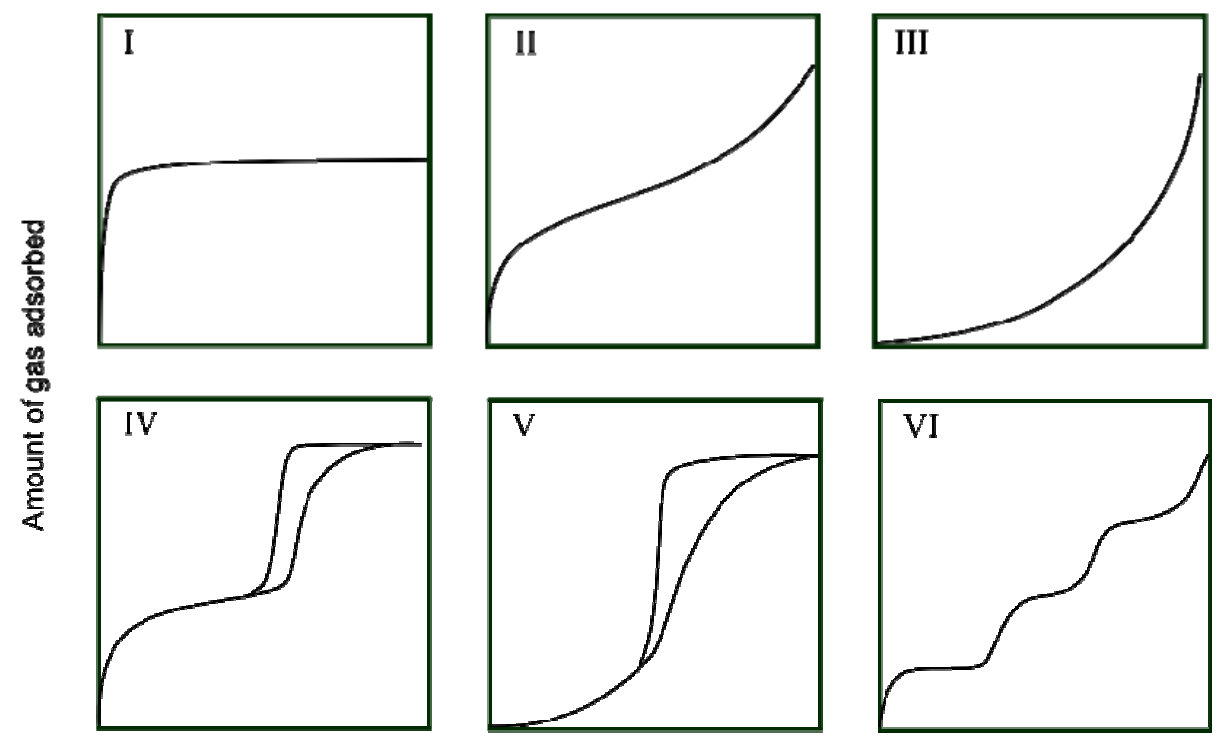

Relative pressure, PIPo

Figure 1. Types of adsorption isotherms according to IUPAC classifications.

Type I isotherms are characteristics of the existence of only strong interactions between the adsorbate and adsorbent, which explains the high adsorption at low relative pressure. In activated carbons, this is due to the existence of micropores. If the isotherm is clearly of type $\mathrm{I}$, the carbon is called "microporous carbon," and it can be assumed that most of the porosity is formed by pores whose widths less than $2 \mathrm{~nm}$. This isotherm is very common in activated carbons. The isotherms of type II are generally associated to non-porous solids (Gregg \& Sing, 1982). But, if the activated carbon has a wide distribution of pore widths (i.e., micropores and mesopores of different widths), the isotherm obtained can be similar to type II but with higher gas adsorption (Yates, 2003). In these cases, it must be thought that this isotherm is a combination of types I and IV. Pure type II represents the multilayer adsorption of a vapor into macropores or external surface. Type IV is an isotherm characteristic of a mesoporous solid and the hysteresis is due to capillary condensation into mesopores. Isotherms types III and V are characteristics for systems where the adsorbentadsorbate interaction is weak compared with adsorbate-adsorbate interactions. As activated carbons are a universal adsorbent and the interactions with adsorbate are never weak, then these isotherms are not frequently found in activated carbons. The same condition applies to type VI which is of theoretical interest but relatively rare in activated carbons. 
There are a lot of theoretical models applied on gas isotherms data, which allow obtaining physical characterization of carbon surfaces (Do et al, 2008). Some of the most used are cited in Table 2.

\begin{tabular}{|l|l|l|}
\hline Model & Determined parameter & Reference \\
\hline $\begin{array}{l}\text { Barret, Joyner and Halenda } \\
\text { (BJH) }\end{array}$ & $\begin{array}{l}\text { Mesopore size } \\
\text { distribution }\end{array}$ & Barret et al. (1951) \\
\hline $\begin{array}{l}\text { Dubinin-Radushkevich (DR) } \\
\text { and Dubinin-Astakhov (DA) }\end{array}$ & Micropore volume & Dubinin et al. (1947) \\
\hline Horvarth-Kawazoe (HK) & $\begin{array}{l}\text { Micropore size } \\
\text { distribution }\end{array}$ & $\begin{array}{l}\text { Hovarth \& Kawazoe } \\
(1983)\end{array}$ \\
\hline $\begin{array}{l}\text { Density Functional Theory } \\
\text { (NLDFT or DFT) }\end{array}$ & Pore size distribution & Olivier (1995) \\
\hline $\begin{array}{l}\text { Brunauer, Emmett and Teller } \\
\text { (BET) }\end{array}$ & Surface area & Brunauer et al. (1938) \\
\hline Langmuir & Surface area & Langmuir (1918) \\
\hline
\end{tabular}

Table 2. Most common isotherm models used in gas adsorption.

One of the most used is that proposed by Brunauer, Emmett, and Teller: the BET model (Brunauer et al., 1938). This model is a two-parameter adsorption equation of the form (Gregg \& Sing, 1982):

$$
\frac{P}{\sigma\left(P_{0}-P\right)}=\frac{1}{\sigma_{0} c}+\frac{c-1}{\sigma_{0} c} \frac{P}{P_{0}}
$$

where $P_{0}$ is the saturation pressure of vapor used, $\sigma$ is the adsorbed quantity at pressure $P$, $\sigma_{0}$ is the monolayer capacity, and $c$ is a constant (at isotherm temperature) that depends on the heat of condensation the heat of adsorption. A plot of $P /\left[\sigma\left(P_{0}-P\right)\right]$ versus $P / P_{0}$ yields a (near) straight line with slope $(c-1) / \sigma_{0} c$ and intercept $1 / \sigma_{0} c$. For type II and IV isotherms, the recommended pressure range is between 0.05 and $0.35 P / P_{0}$ and from 0.02 to 0.12 for type I. If the molecular area occupied by the adsorbed gas is known, the surface area can be calculated from $\sigma_{0}$. The value of $c$ gives information about the adsorbate-adsorbent interaction. When $c$ increases, the interaction is stronger, relative to interactions between molecules of adsorbate, or, in other words, the isotherm type changes from type III (low c) to type II (medium $c$ ) and, finally, type I (high value of $c$ ). Care should be taken in analysing data, since type III and type $\mathrm{V}$ isotherms are not adequate for this mathematical approach.

The most used gas is $\mathrm{N}_{2}$ (molecular area, $0.162 \mathrm{~nm}^{2}$ ) at $77 \mathrm{~K}$, but other vapors have been employed from time to time. The different molecular sizes (and shapes) cause that not all gases can access at the same pores. It is evident that this procedure must lead to anomalous results for the area of a given solid if different gases are used. Prior to the determination of an isotherm, all physisorbed material must be removed from the surface. This is achieved by exposure of the solid to high vacuum and heat. The exact temperature and residual pressure can condition the final results. 


\section{Proximate analysis}

Proximate analysis is one of the thermal analysis techniques. These are analytical techniques in which a physical property is measured with a temperature-programmed variation. In this case, the property measured is the weight.

Proximate analysis provides an approach to estimate the content of: a) moisture; b) volatile matter; c) fixed carbon; and d) ash. There are some standard methods (for example, ASTM, DIN, UNE), but the analysis is usually carried out in an automated thermogravimetric system. Moisture measurements refer to the matter volatilized until near $373 \mathrm{~K}$ in an inert atmosphere, mostly water. Volatile matter is determined by the same procedure but in a temperature range of 373 to $1223 \mathrm{~K}$. Fixed carbon is the material burned in air at $1223 \mathrm{~K}$ in a third step and is made of the more stable organic structures. Lastly, the non-combustible matter is the ash. Generally, the composition of ash, fixed carbon, and volatile matter are given on a dry basis. The representation of weight versus temperature (or time) also gives information about the thermal stability of the activated carbon.

The proximate analysis is susceptible of variations in the thermal treatment. Generally, when temperature or time increases, the volatile matter content decreases. The effect of this is that both the ash content and the fixed carbon content increase as a consequence of the concentration of the inorganic fraction and carbon in charcoal (Duran-Valle et al., 2006).

As in the elemental analysis, this technique does not give accurate information about functional groups but can provide limited information on chemical structure (see Table 3). A better and related technique is thermal programmed desorption, in which desorbed species produced at heating are analyzed (see below).

\begin{tabular}{|l|l|l|}
\hline Element & Low content & High content \\
\hline Moisture & $\begin{array}{l}\text { High HHV } \\
\text { Low graphitization grade }\end{array}$ & Low HHV \\
\hline Folatile matter & $\begin{array}{l}\text { High graphitization grade } \\
\text { Low amount of functional groups }\end{array}$ & $\begin{array}{l}\text { High graphitization grade } \\
\text { High HHV } \\
\text { High amount of functional groups }\end{array}$ \\
\hline Ash & $\begin{array}{l}\text { Low graphitization grade } \\
\text { High amount of functional groups }\end{array}$ & $\begin{array}{l}\text { High graphitization grade } \\
\text { Low amount of functional groups }\end{array}$ \\
\hline
\end{tabular}

Table 3. Information about the chemistry of carbon obtained from proximate analysis.

\section{Elemental analysis}

Elemental analysis is the primary method to obtain knowledge about carbon chemistry (Bandosz, 2009). This technique does not provide details on functional groups but at least gives information about heteroatom content and it can provide approximate information on chemical structure, see Table 3 (Chingombe et al., 2005), graphene size (Duran-Valle, 2006), 
and pore structure (Pastor-Villegas et al., 1998). There are two types of elemental analysis: organic and inorganic. The organic elemental analysis is accomplished by combustion analysis and generally determines carbon, hydrogen, nitrogen, sulphur, and, by difference, oxygen; observations about each one are reported in Table 4.

\begin{tabular}{|l|l|l|}
\hline Element & Low content & High content \\
\hline C & $\begin{array}{l}\text {-Low higher heating value } \\
\text {-Low graphitization grade }\end{array}$ & $\begin{array}{l}\text {-High HHV } \\
\text {-High graphitization grade } \\
\text {-Low amount of functional groups } \\
\text {-Probably non-polar surface (with low content } \\
\text { of O and N) } \\
\text {-Probably basic surface (with low content of O) }\end{array}$ \\
\hline H & -High graphitization grade & -Low graphitization grade \\
\hline O & $\begin{array}{l}\text {-Low amount of oxygenated } \\
\text { functional groups }\end{array}$ & $\begin{array}{l}\text {-High amount of functional groups } \\
\text {-Polar surface } \\
\text {-Acidic surface }\end{array}$ \\
\hline $\mathrm{N}$ & --- & $\begin{array}{l}\text {-Polar surface } \\
\text {-Basic surface }\end{array}$ \\
\hline
\end{tabular}

Table 4. Information about the chemistry of carbon obtained from organic elemental analysis.

The inorganic elemental analysis yields information about inorganic material (ashes in carbon materials, supported catalysts) and can be carried out by various techniques, based mainly on X-ray, electron, or mass spectroscopy. Related with elemental analysis is radioactive characterization (Rubio-Montero et al., 2009), this is a promising method to differentiate between charcoals (carbonized biomass) and coals.

\section{Acid/base titration}

One of the most influential variables in the adsorption in solution is the $\mathrm{pH}$, since this parameter can change the sign (or presence) of charges onto the adsorbate. On the surface of activated carbon, the predominant charge (positive or negative) depends on the acidic or basic character of the adsorbent. Therefore, it is important to study the presence of acidic or basic functional groups on activated carbons.

A global measurement of the acidity/basicity of a carbon is the point of zero charge (PZC) at which the surface charge density is 0 (IUPAC, 1997). It is usually determined in relation to a disolution's $\mathrm{pH}$ : the $\mathrm{pH}$ of the solution at equilibrium with a solid when the solid exhibits zero net electrical charge on the surface. A very similar concept is the isoelectric point (IEP), which requires that the charge is 0 in the entire solid, not only on the surface. Generally, IEP is very similar to PZC. The PZC can be obtained from acid-base titrations of dispersions and monitoring the electrophoretic mobility of the particles and the solution $\mathrm{pH}$. The titration of 
several dispersions of activated carbons in aqueous solutions with different initial pHs is easier and cheaper. A plot of final $\mathrm{pH}$ versus initial $\mathrm{pH}$ of the solutions with and without activated carbon gives a cross that indicates the PZC (see Figure 2).

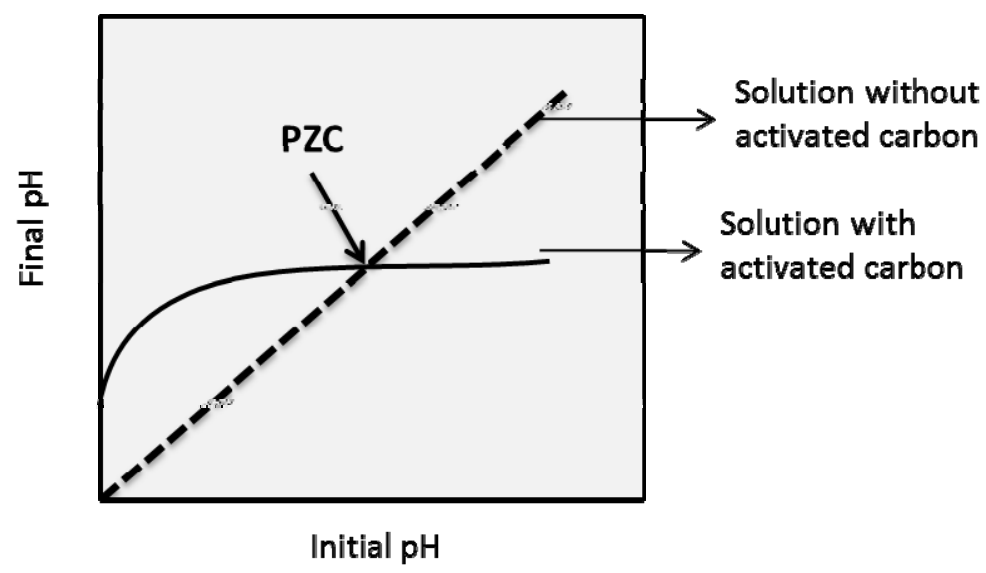

Figure 2. PZC measurement determined in several solutions at different initial pHs.

Another method is also mass titration with only a solution (whose $\mathrm{pH}$ in this method is irrelevant) and with at least $7 \%$ (w/v) activated carbon (Valente-Nabais \& Carrot, 2006). The $\mathrm{pH}$ of the solution is approaching to the PZC when the carbon quantity increases. With $7 \%$ $(\mathrm{w} / \mathrm{v})$ of activated carbon, the equilibrium is reached. Then, the solution $\mathrm{pH}$ is the PZC of the adsorbent (see Figure 3).

A more detailed assessment of the acidity/basicity is performed by titration with several substances of different acidities. As an example, in the method proposed by Boehm (Boehm, 2002), the amount of oxygen-containing groups (carboxyl, lactonic, phenol, and others) was determined by adsorption neutralization with $\mathrm{NaHCO}_{3}, \mathrm{Na}_{2} \mathrm{CO}_{3}, \mathrm{NaOH}$, and $\mathrm{NaOCH}_{2} \mathrm{CH}_{3}$ solutions, respectively. Also, the basic group content can be determined with $\mathrm{HCl}$ solution. This method, widely used, has several drawbacks. As in all classic titrations with solids (especially with microporous solids), the equilibrium time is very long. There may be functional groups with the same structure and very different acidities, or different functional groups with similar acidities (for example, 2,4-dinitrophenol and benzoic acid have a similar $\mathrm{pK}_{\mathrm{a}}$ ). This prevents quantification of functional groups in its structure, although it could be realized by acid strength. Another failure is that functional groups containing other heteroatoms are considered as oxygen functional groups. The acidic or basic functional groups can be also characterized by immersion calorimetry (López-Ramón et al., 1999). 


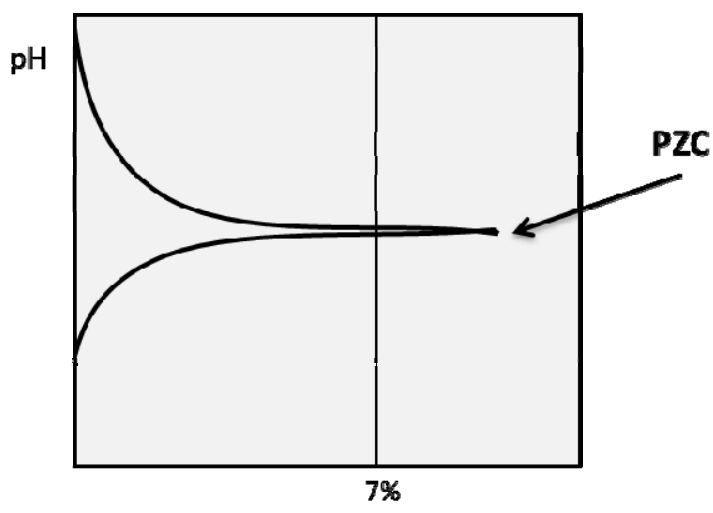

Actlvated carbon, $\%, w / v$

Figure 3. Determination of PZC by Valente-Nabais \& Carrott method. Variation of activated carbon $\mathrm{w} / \mathrm{v}$.

\section{Thermal Programmed Desorption (TPD)}

TPD is a thermal analysis method widely used for the characterization of activated carbons. In this technique, a sample is heated in a carrier gas, to induce thermal desorption of adsorbed species or thermal decomposition. The desorbed products are analyzed by several methods. By heating, the oxygenated groups are thermally decomposed, releasing $\mathrm{CO}, \mathrm{CO}_{2}$, and $\mathrm{H}_{2} \mathrm{O}$ at different temperatures. The groups can be identified by decomposition temperature and type of gas and can be quantified by the areas of peaks. The major difficulty is the identification of each surface group, because in activated carbons TPD spectra show composite and broad peaks of all gases released. An application of this technique with several references is shown in (Figueiredo et al., 1999).

\section{Calorimetric Techniques}

There are a set of techniques that measure the heat involved in a process (Bandosz, 2009). Such techniques have been used to estimate some aspects of the physical and the chemical structure of activated carbons. Immersion calorimetry provides a measurement of the energy involved in the interaction of molecules of a liquid with the surface of activated carbon. The use of several liquids with different polarities can be related with the hydrophobic and hydrophilic nature of the surface. The enthalpy of immersion of carbonaceous materials into water can give information about primary adsorption centers that are related to the oxygen content (Stoeckli et al., 1983). The differential scanning calorimetry (DSC) measures the difference in the amount of heat required to increase the temperature of a sample and a reference sample as a function of temperature. A similar technique is the differential thermal analysis; in this, the difference in temperature between sample and reference is the parameter measured. Both techniques can be used to evaluate the thermal behavior of a charcoal (Duran-Valle et al., 2005). 


\section{Infrared Spectroscopy (FTIR)}

Infrared spectroscopy is a traditional method for structural analyses of organic compounds, where infrared radiation is absorbed selectively by the various bonds within a compound. Since FTIR spectroscopy can detect specific bonds in a material, then it is possible to know which functionalities exist on the surface of carbon. IR spectroscopy has been used to study, for example, the changes in the surface chemical structure of the carbon materials after oxidation (Chingombe et al., 2005; Moreno-Castilla et al., 2000; Pradhan \& Sandle, 1999), reactions with alkali (Lillo-Ródenas et al., 2003), the carbonization and activation process (Pastor-Villegas et al., 1999), or in the chemical activation of wood (Solum et al., 1995). FTIR is mainly used as a qualitative technique for the analysis of the chemical structure of activated carbons and, sometimes, as quantitative technique (Bandosz, 2009). Two problems are associated with this technique $-a)$ the opacity of carbons and b) the broad peaksbecause they are usually a sum of interactions of similar types of functional groups. This technique was used intensively on carbonaceous materials when equipments with Fourier transform (FT) were accessible. The FT allows an improvement over signal/noise rate, energy throughout, accuracy, and fast scans. This approach partially eliminated the opacity problem. Better results can be obtained with alternative techniques (López \& Márquez, 2003) that allow reflection (rather than transmission) on activated carbon surfaces - for example, specular reflectance, diffuse reflectance (DRIFT), attenuated total reflectance (ATR), or photoacustic spectroscopy (FTIR-PAS). The assignment of the IR bands to different functional groups is made by comparison with adsorption/transmission bands of organic compounds (Bellamy, 1986; Smith, 1999). The width of the bands is due to the existence of several similar bands with a maximum at different frequencies, because they are affected by vicinal functionalities. Table 5 shows the approximate assignment of main bands in charcoals IR spectra.

\begin{tabular}{|l|l|l|}
\hline Wavenumber $\left(\mathrm{cm}^{-1}\right)$ & Assignment & Structures \\
\hline $3600-3000$ & Stretching O-H, N-H & Hydroxyl, carboxilic acid \\
\hline $3000-2800$ & Stretching C-H & $\begin{array}{l}\text { Alifatic, olefinic and } \\
\text { aromatic hidrocarbons }\end{array}$ \\
\hline $1770-1650$ & Stretching C=O & Carbonyl \\
\hline $1700-1600$ & Stretching C=C & Olefinic structures \\
\hline $1650-1500$ & Stretching C=C & Aromatic structures \\
\hline $1480-1420$ & Bending C-H & Alifatic structures \\
\hline $1430-1360$ & Bending O-H and C-H & $\begin{array}{l}\text { Hydroxyl, carboxilic acid, } \\
\text { olefines, methyl }\end{array}$ \\
\hline $1300-1200$ & Stretching C-O & Unsaturated ethers \\
\hline $1160-1050$ & Stretching C-O & Tertiary hydroxyl \\
\hline $1120-1070$ & Stretching C-O & Secondary hydroxyl \\
\hline $1060-1000$ & Stretching C-O & Primary hydroxyl \\
\hline $900-700$ & Bending out of the plane C-H & Aromatic structures \\
\hline
\end{tabular}

Table 5. Assignment of bands in IR spectra of charcoals. 


\section{X-Ray Photoelectron Spectroscopy (XPS)}

XPS (also known as ESCA, electron spectroscopy for chemical analysis) is a technique frequently used in surface chemistry. XPS measures the energy of internal atomic orbitals. This value is characteristic of each element, and so, XPS gives information about elemental composition. But, this value changes slightly with the electric charge on the atom. Therefore, XPS also gives information about functional groups in activated carbons. An important feature of this technique is that the analysis is limited to the surface (some nanometers). This feature can be positive (for surface chemistry studies) or negative (if surface contamination exits). This fact is typical of a spectroscopic technique that uses electrons in their mechanism, because the electrons interact with materials more than photons of the same energy, and so, electrons can pass through a smaller amount of material (in XPS, $0.4-4 \mathrm{~nm}$, depending on the kinetic energy of the electron).

XPS uses monochromatic X-ray photons to excite an inner-shell electron. This electron can be extracted out of the atom, and its kinetic energy can be measured. The kinetic energy depends on the binding energy. The mechanism of the process is shown in Figure 4. An incident photon (given is clear color) of energy $h v$ is absorbed by an atom, and an electron (given in dark color) placed in an orbital of bind energy $E_{b}$ leaves the atom with a kinetic energy $\mathrm{E}_{\mathrm{e}}$. The energy of the photon is divided between the energy to translate the electron to the Fermi level $\left(E_{b}\right)$, the kinetic energy, and a correction factor, the work function $(w)$, which depends on the equipment. The energy equation is:

$$
h v=E_{b}+E_{e}+w
$$

All data except $E_{b}$ are experimentally known, and $E_{b}$ can be easily calculated. The intensity of the peaks is related to the concentration of the element, and quantitative analysis (of the surface) can be carried out.

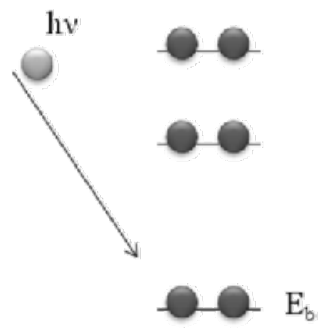

a

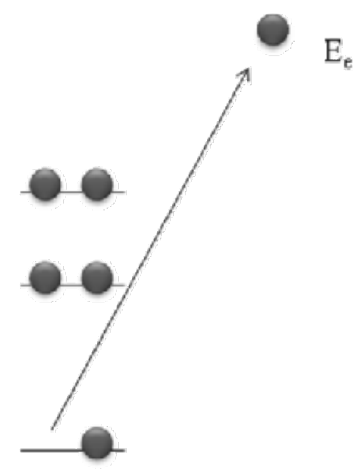

b

Figure 4. Mechanism of X-Ray Photoelectron Spectroscopy. 
In activated carbons, XPS is used to characterize surface functionalities (Bandosz, 2009; Chingombe et al., 2005; Moreno-Castilla et al., 2000) employing binding energies of the C 1s, $\mathrm{N}$ 1s, and $\mathrm{O}$ 1s photoelectrons (Figueiredo et al., 1999). A comparison with elemental analyses can yield information about different compositions in the surface and into the bulk (Figueiredo et al., 1999).

Table 6 shows an interpretation of peaks of C 1s XPS spectra. Assignment of peaks in N 1s spectra is more difficult due to the large variety of species (with different oxidation states) that nitrogen atoms can form. The value of binding energy varies between $399 \mathrm{eV}$ (reduced form of nitrogen, as amines) to $404 \mathrm{eV}$ (oxidized form of nitrogen, as nitro groups or nitrate). The assignment of peaks for $\mathrm{O} 1 \mathrm{~s}$ spectra is easier, because generally only three bands can be distinguished: near $532 \mathrm{eV}$ (double bond $\mathrm{C}=\mathrm{O}$ ), $534 \mathrm{eV}$ (single bond C-O), and $536 \mathrm{eV}$ (water occluded) (Lin et al., 2008).

Two similar techniques are UPS (ultraviolet photoelectron spectroscopy), where photons have energy until $50 \mathrm{eV}$ which allows to be used to study external orbitals (RaymundoPiñero et al., 2002); and SXPS (soft X-ray photoelectron spectroscopy), which uses photons with energy from 50 to $150 \mathrm{eV}$.

\begin{tabular}{|l|l|}
\hline $\begin{array}{l}\text { Binding energy }(\mathrm{eV}) \\
\text { (approximate) }\end{array}$ & Assignment \\
\hline 285.0 & $\begin{array}{l}\text { Aromatics and aliphatics structures. Carbon atoms bond to } \\
\text { hydrogen or carbon atoms }\end{array}$ \\
\hline 286.0 & Single $\mathrm{C}-\mathrm{O}$ bond (alcohol, ether) \\
\hline 287.5 & Double $\mathrm{C}=\mathrm{O}$ bond (carbonyl) \\
\hline 289.0 & O-C=O (carboxyl, ester) \\
\hline 290.5 & Carbonate, $\mathrm{CO}_{2}$ \\
\hline 291.5 & Plasmon \\
\hline
\end{tabular}

Table 6. Assignment of peaks in C 1s XPS spectra.

\section{X-Ray diffraction (XRD)}

Activated carbons contain short-range ordered structures, then XRD can provide details about the crystallites or micrographites into the carbon structure, including the disordered and defective features (Burian et al., 2005). This information is obtained from the distribution of scattered radiation using X-rays. The observed diffraction pattern may be converted to structural data, so XRD is used not only to estimate crystallite size or graphitization degree in carbonaceous materials (Biniak et al., 2010; Pradhan \& Sandle, 1999) but also used to characterize the inorganic material (Pastor-Villegas et al., 1999). The degree of graphitization is an important parameter, since it reflects the transition extent of carbon material from turbostratic to graphitic structure, and determines some properties of the material (Hussain et al., 2000; Zou et al., 2003).

Generally, the $\left(\begin{array}{lll}0 & 0 & 2\end{array}\right)$ line is used to determine the interlayer spacing $d_{(002)}$ according to the Bragg equation. A method for calculating the degree of graphitization $(g)$ can be done by using the following equation (Maire \& Mering, 1970): 


$$
g(\%)=\frac{0.3440-d_{(002)}}{0.3440-0.3354} \times 100
$$

where $0.3440(\mathrm{~nm})$ is the interlayer spacing of the non-graphitized carbon and $0.3354(\mathrm{~nm})$ is the interlayer spacing of an ideal-type graphite crystallite.

Other method uses the surface under two peaks (Johnson, 1959). The first of these peaks (A) is broad and situated at low $2 \theta$ values (maximum near 20 degrees), and it is indicative of the amorphous nature of the material. The second peak (C) is situated near 25 degrees, is higher and narrower, and indicates the presence of crystallinity. The equation used is:

$$
g(\%)=\frac{I_{C}}{I_{A}}+K I_{A}
$$

where $I_{C}$ is the integrate of peak $C, I_{A}$ is the integrate of peak $A$, and $K$ is a constant.

\section{Other X-Ray techniques}

There are other techniques of characterization of activated carbons than X-ray radiation, but they are not as commonly used as XRD or XPS. Some of these techniques are described below.

\subsection{X-ray fluorescence (XRF)}

$\mathrm{XRF}$ is the emission of characteristic $\mathrm{X}$-ray radiation from a material that has been excited by bombarding it with X-ray or gamma photons. The term fluorescence is applied when the absorption of radiation of a specific energy results in the emission of radiation of a different (generally lower) energy. This technique is widely used for elemental analysis, but it gives more limited information that obtained in XPS. The mechanism of this phenomenon is shown in Figure 5, which can be considered as a continuation from Figure 4b. Later than when an electron is expulsed of an atom absorbing the energy of a photon (Figure 5a), a hole is created on the lower orbital. An electron of a higher orbital "falls" into the lower orbital (Figure 5b), and energy is released in the form of a photon (Figure 5c). The energy of this photon is equal to the energy difference of the two orbitals involved, and this quantity is characteristic of this element.
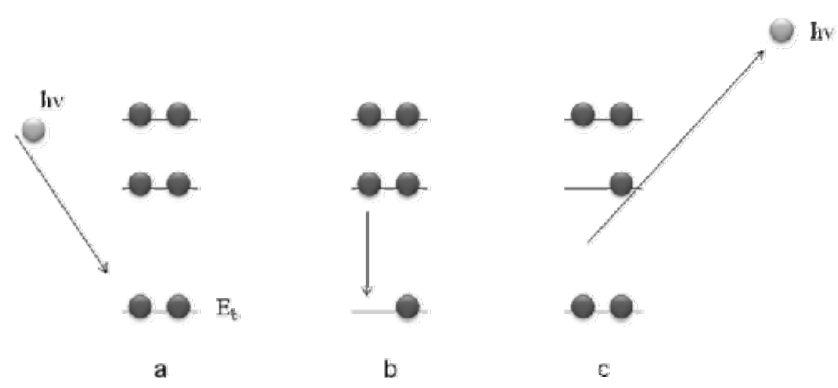

Figure 5. Mechanism of X-ray fluorescence. 


\subsection{Small-angle X-ray scattering (SAXS)}

Small-angle X-ray scattering is a technique where the scattering of X-ray photons by a sample that has inhomogeneities in the nm scale is detected at very low angles. This angular range contains information about pores in activated carbon (Bóta et al., 1997). This technique yields information about physical structure, as XRD, but not about composition, as XPS.

\subsection{EDX-SEM}

A variation of $\mathrm{XRF}$ is the energy-dispersive $\mathrm{X}$-ray spectroscopy (EDX), which is commonly connected to scanning electron microscopes (SEMs). The union of these two techniques allows a point elemental analysis of a surface and also makes a "map" of elemental composition of a surface. This technique is mainly used to study the content and dispersion of metals on a carbon surface.

With illustrative purposes, Figure 6 shows an SEM image (top left) of an activated carbon doped with a sulphur-containing dye. The next figures are the same sample but "tuned" in an element. It can be seen at some points that the concentration of several heteroatoms is high, and these points can be assigned to mineral matter.
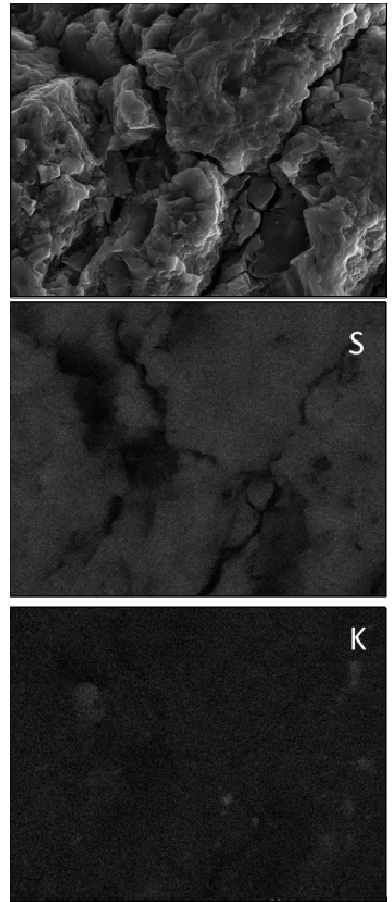
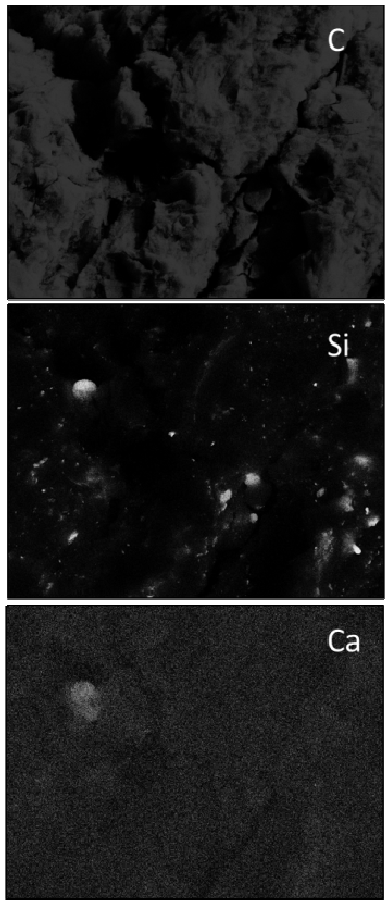
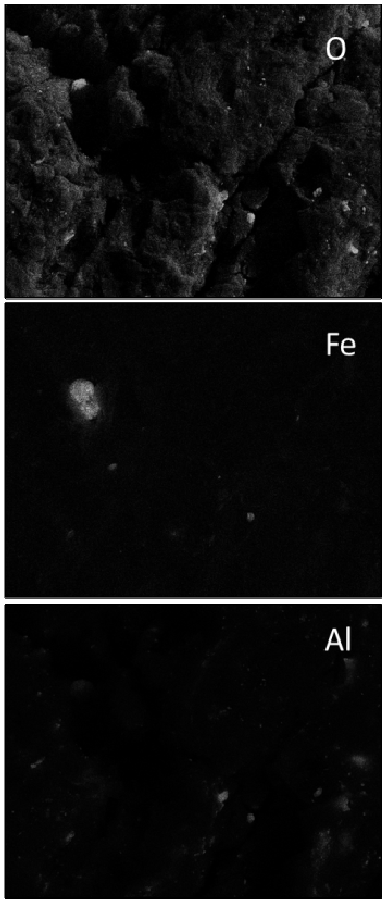

Figure 6. EDX-SEM images of an activated carbon treated with acid blue 25. Image courtesy of Servicio de Apoyo a la Investigación de la Universidad de Extremadura (Badajoz, Spain). Sample supplied by the Instituto Tecnológico de Aguascalientes (Aguascalientes, Mexico). 


\section{Micro Raman spectroscopy}

Raman spectroscopy is used to study vibrational and rotational modes in a system. It is related with FTIR, and both techniques are usually complementary. Laser Raman spectroscopy is used on carbonaceous materials to evaluate the degree of graphitization (Zou et al., 2003) and not for functional groups determination. Micro laser Raman spectroscopy allows to analyze a microscopic surface area of interest. It is an alternative technique to XRD for studying the graphitization extension of a carbonaceous material (Cuesta et al., 1994). In Raman spectra of most activated carbons, two peaks are generally obtained: 1360 and $1580 \mathrm{~cm}^{-1}$. The last one corresponds to graphite structure, and the 1360 $\mathrm{cm}^{-1}$ is correlated with a disordered carbon structure. The ratio of the integrated intensities $\left(\mathrm{I}_{1360} / \mathrm{I}_{1580}\right)$ has been considered to be a good parameter to estimate the disorder in the structure.

\section{Nuclear Magnetic Resonance (NMR)}

NMR is a technique based on measurements of absorption of electromagnetic radiation related with atom nuclei into a magnetic shield. Its use in activated carbon analysis (and other solids) has increased due to the magic-angle spinning (MAS) method that solves the problems of lack of resolution due to the solid state. Generally, the ${ }^{13} \mathrm{C}$ spectrum is the most used. The obtained information includes the hybridization of carbon atoms and the presence of oxygenated functional groups. ${ }^{13} \mathrm{C}-\mathrm{NMR}$ can give the aromatic-to-aliphatic carbon ratio and is useful to study changes in surface chemistry (Solum et al., 1995), including heteroatoms. Also, NMR can be used to study compounds adsorbed on carbon surfaces if these compounds have atoms that are different from carbon.

\section{Conclusions}

Activated carbons have been used for a long time as adsorbents. It is now recognized that activated carbons offer unparallel flexibility in tailoring their physical and chemical properties to specific needs, thus showing the remarkably wide range of potential applications.

The simultaneous use of several physicochemical characterization techniques is very common, and there are a lot of examples in publications. This is due to no one technique may provide all the necessary information about surfaces, together with the extremely complex structures (physical and chemical) of carbon. However, the structure of these materials is not well understood, and more research about the analysis of porous carbonaceous materials is needed.

Traditionally, techniques used in the study of physical structure and those techniques used in the study of chemical structure have been distinguished. But, it has been shown that often both structures are related. It is advisable to conduct a comprehensive study of the activated carbons to better understand their properties. 


\section{Acknowledgments}

The author thanks the support of Spanish Government (CTM2010-14883/TECNO and CTM2010-17776), Junta de Extremadura/FEDER (GRU10011), and Instituto Tecnológico de Aguascalientes (Mexico).

\section{References}

[1] Bandosz, T.J. (2009). Surface Chemistry of Carbon Materials. In Carbon Materials for Catalysis. Serp, P., \& Figueiredo, J.L. (Eds.). pp. (58-78), Wiley, ISBN 978-0-470-17885-0.

[2] Barrett, E.P., Joyner, L.G. \& Halenda, P.P. (1951). The determination of pore volume and area distributions in porous substances. I. Computations from nitrogen isotherms. Journal of the American Chemical Society, Vol. 73, No. 1, (January 1951), pp. (373-380), ISSN 0002-7863.

[3] Bellamy, L.J. (1986). The infrared spectra of complex molecules. Chapman and Hall, ISBN 0412138506, USA.

[4] Biniak, S., Pakuła, M., Świątkowski, A., Bystrzejewski, M. \& Błażewicz, S. (2010). Influence of high-temperature treatment of granular activated carbon on its structure and electrochemical behavior in aqueous electrolyte solution. Journal of Material Research, Vol. 25, No.8, (August 2010), pp. (1617-1628), ISSN 0884-2914.

[5] Boehm, H.P. (2002). Surface oxides on carbon an their analysis : a critical assessment. Carbon, Vol. 40, No. 2, (February 2002), pp. (145-149), ISSN 0008-6223.

[6] Bóta, A., László, K., Nagy, L.G. \& Copitzky, T. (1997). Comparative study of active carbons from different precursors. Langmuir, Vol. 13, No. 24, (November 1997) pp. (6502-6509), ISSN 0743-7463.

[7] Brunauer, S., Deming, L.S.; Deming, W.S. \& Teller, E. (1940). On a Theory of the van der Waals Adsorption of Gases. Journal of the American Chemical Society, Vol. 62, No. 7, (July 1940), pp. (1723-1732), ISSN 0002-7863.

[8] Brunauer, S., Emmett, P.H. \& Teller, E. (1938). Adsorption of Gases in Multimolecular Layers. Journal of the American Chemical Society, Vol. 60, No. 2, (February 1938), pp. (309319), ISSN 0002-7863.

[9] Burian, A., Dore, J.C., Hannon, A.C. \& Honkimaki, V. (2005). Influence of hightemperature treatment of granular activated carbon. Journal of Alloys and Compounds, Vol. 401, No. 1-2, (September 2005), pp. (18-23), ISSN 0925-8388.

[10] Calvino-Casilda, V., López-Peinado, A.J., Durán-Valle, C.J. \& Martín-Aranda, R.M. (2010). Last Decade of Research on Activated Carbons as Catalytic Support in Chemical Processes. Catalysis Reviews: Science and Engineering, Vol. 52, No. 3, (2010), pp. (325-380), ISSN 0161-4940.

[11] Chingombe, P., Saha, B. \& Wakeman, R.J. (2005). Surface modification and characterisation of a coal-based activated carbon. Carbon, Vol. 43, No. 15, (December 2005), pp. (3132-3143), ISSN 0008-6223.

[12] Cuesta, A., Dhamelincourt, P., Laureyns, J., Martínez-Alonso, A. \& Tascón, J.M.D., (1994). Raman microprobe studies on carbon materials. Carbon, Vol. 32, No. 8, (1994), pp. (1523-1532), ISSN 0008-6223.

[13] Do, D.D. (1998). Adsorption Analysis: Equilibria and Kinetics. Imperial College Press, ISBN 1-86094-130-3, London. 
[14] Do, D.D.; Ustinov, E.A. \& Do, H.D. (2008). Porous Texture Characterization from GasSolid Adsorption. In: Adsorption by Carbons. Bottani, E.J. \& Tascón, J.M.D. (Eds.). pp. (240-270), Elsevier Ltd., ISBN 978-0-08-044464-2, UK.

[15] Dubinin, M.M., Zaverina, E.D. \& Radushkevich, L.V. (1947). Sorption and structure of active carbons. I. Adsorption of organic vapors. Zhurnal Fizicheskoi Khimii, Vol. 21, (1947), pp. (1351-1362), ISSN 0044-4537.

[16] Durán-Valle, C.J. (2006). Geometrical relationship between elemental composition and molecular size in carbonaceous materials. Applied Surface Science, Vol. 252, No. 17, (June 2006), pp. (6097-6101), ISSN 0169-4332.

[17] Durán-Valle, C.J., Gómez-Corzo, M., Gómez-Serrano, V., Pastor-Villegas, J. \& RojasCervantes, M.L. (2006). Preparation of charcoal from cherry stones. Applied Surface Science, Vol. 252, No. 17, (June 2006), pp. (5957-5960), ISSN 0169-4332.

[18] Durán-Valle, C.J., Gómez-Corzo, M., Pastor-Villegas, J. \& Gómez-Serrano, V. (2005). Study of cherry stones as raw material in preparation of carbonaceous adsorbents. Journal of Analytical and Applied Pyrolysis, Vol. 73, No. 1, (March 2005), pp. (59-67), ISSN 0165-2370.

[19] Figueiredo, J.L.; Pereira, M.F.R.; Freitas, M.M.A. \& Orfao, J.J.M. (1999). Modification of the surface chemistry of activated carbons. Carbon, Vol. 37, No. 9, (1999), pp. (13791389), ISSN 0008-6223.

[20] Gregg, S.J. \& Sing, K.S.W. (1982). Adsorption, Surface Area and Porosity. 2nd edition. Academic Press, ISBN 0-12-300956-1, London.

[21] Hovarth, G. \& Kawazoe, K. (1983). Method for the calculation of effective pore size distribution in molecular sieve carbon. Journal of Chemical Engineering of Japan, Vol. 16, No. 6, (1983), pp. (470-475), ISSN 0021-9592.

[22] Hussain, R., Qadeer, R., Ahmad, M., \& Saleem, M. (2000). X-Ray Diffraction Study of Heat-Treated Graphitized and Ungraphitized Carbon. Turkish Journal of Chemistry, Vol. 24, No. 2, (June 2000), pp. (177-83), ISSN 1300-0527.

[23] IUPAC (1972). Manual of Symbols and Terminology, appendix 2, Pt.1, Colloid and Surface Chemistry. Pure and Applied Chemistry, Vol. 31, No. 4, (1972), pp. (578-638), ISSN1365-3075.

[24] IUPAC, (1997). Compendium of Chemical Terminology, 2nd ed. (the "Gold Book"). Compiled by A. D. McNaught \& A. Wilkinson. Blackwell Scientific Publications, Oxford (1997). XML on-line corrected version: http://goldbook.iupac.org (2006-) created by M. Nic, J. Jirat, B. Kosata; updates compiled by A. Jenkins. ISBN 0-9678550-9-8.

[25] Johnson, J.E. (1959). X-ray diffraction studies of the crystallinity in polyethylene terephthalate. Journal of Applied Polymer Science, Vol. 2, No. 5, (September/October 1959), pp. (205-209), ISSN 0021-8995.

[26] Langmuir I. (1918). The adsorption of gases on plane surfaces of glass, mica and platinum. Journal of the American Chemical Society, Vol. 40, No. 9, (September 1918), pp. (1361-1403), ISSN 0002-7863.

[27] Lillo-Ródenas, M.A., Cazorla-Amorós, D. \& Linares-Solano, A. (2003). Understanding chemical reactions between carbons and $\mathrm{NaOH}$ and $\mathrm{KOH}$ : An insight into the chemical activation mechanism. Carbon, Vol. 41, No. 2, (February 2003), pp. (267-275), ISSN 0008-6223.

[28] Lin, H.Y., Chen, W.C., Yuan, C.S. \& Hung, C.H. (2008). Surface Functional Characteristics (C, O, S) of Waste Tire-Derived Carbon Black before and after Steam Activation. Journal of the Air \& Waste Management Association, Vol. 58, No. 1, (1958), pp. (78-84). ISSN 1047-3289. 
[29] López, A \& Márquez, C. (2003). Espectroscopía Infrarroja. In: Técnicas de análisis y caracterización de materiales. Faraldos, M., \& Goberna, C. (Eds.). pp. (181-1859), CSIC, ISBN 84-00-08093-9.

[30] Lopez-Ramon, M.V., Stoeckli, F., Moreno-Castilla, C. \& Carrasco-Marin, F. (1999). On the characterization of acidic and basic surface sites on carbons by various techniques. Carbon, Vol. 37, No. 8, (January 1999), pp. (1215-1221), ISSN 0008-6223.

[31] Maire, J. \& Mering, J. (1970). Graphitization of soft carbons. In : Chemistry and Physics of Carbon. Walker, P.L. (ed.). pp. (125-189), Marcel Dekker, ISSN 0069-3138.

[32] Moreno-Castilla, C. (2004). Adsorption of organic molecules from aqueous solutions on carbon materials. Carbon, Vol. 42, No. 1, (2004), pp. (83-94), ISSN 0008-6223.

[33] Moreno-Castilla, C., López-Ramón, M.V. \& Carrasco-Marín, F. (2000). Changes in surface chemistry of activated carbons by wet oxidation. Carbon, Vol. 38, No. 14, (2000), pp. (1995-2001), ISSN 0008-6223.

[34] Olivier, J. (1995). Modeling physical adsorption on porous and nonporous solids using density functional theory. Journal of Porous Materials, Vol. 2, No. 1, (June 1995), pp. (917), ISSN 1380-2224.

[35] Pastor-Villegas, J. \& Durán-Valle, C.J. (2002). Pore structure of activated carbons prepared by carbon dioxide and steam activation at different temperatures from extracted rockrose. Carbon, Vol. 40, No. 3, (March 2002), pp. (397-402), ISSN 0008-6223.

[36] Pastor-Villegas, J., Durán-Valle, C.J., Valenzuela-Calahorro, C. \& Gómez-Serrano, V. (1998). Organic chemical structure and structural shrinkage of chars prepared from rockrose. Carbon, Vol. 36, No. 9, (September 1998), pp. (1251-1256), ISSN 0008-6223.

[37] Pastor-Villegas, J., Gómez-Serrano, V., Durán-Valle, C.J. \& Higes-Rolando, F.J. (1999). Chemical study of extracted rockrose and of chars and activated carbons prepared at different temperatures. Journal of Analytical and Applied Pyrolysis, Vol. 50, No. 1, (April 1999), pp. (1-16), ISSN 0165-2370.

[38] Pradhan, B.K. \& Sandle, N.K. (1999). Effect of different oxidizing agent treatments on the surface properties of activated carbons. Carbon, Vol. 37, No. 8, (January 1999), pp. (1323-1332), ISSN 0008-6223.

[39] Raymundo-Piñero, E., Cazorla-Amorós, D., Linares-Solano, A., Find, J., Wild, U. \& Schlögl, R. Structural characterization of N-containing activated carbon fibers prepared from a low softening point petroleum pitch and a melamine resin. Carbon, Vol. 40, No. 4, (April 2002), pp. (597-608), ISSN 0008-6223.

[40] Rubio-Montero, M.P., Durán-Valle, C.J., Jurado-Vargas, M., \& Botet-Jiménez, A. (2009). Radioactive content of charcoal. Applied Radiation and Isotopes, Vol. 67, No. 5, (May 2009), pp. (953-956), ISSN 0969-8043.

[41] Scheele, C.W. (1780). Chemical Observations and Experiments on Air and Fire. J. Johnson, ISBN 9781171413929, London.

[42] Shen, W., Li, Z., \& Liu, Y. (2008). Surface Chemical Functional Groups Modification of Porous Carbon. Recent Patents on Chemical Engineering, Vol. 1, No. 1, (January 2008), pp. (27-40), ISSN 2211-3347.

[43] Sing, K.S.W., Everett, D.H., Haul, R.A.W., et al. (1985). Reporting physisorption data for gas/solid systems with special reference to the determination of surface area and porosity (Recommendations 1984). Pure and Applied Chemistry, Vol. 57, No. 4, (1985), pp. (603-619), ISSN 1365-3075. 
[44] Smith, B.C. (1999). Infrared spectral interpretation: a systematic approach. CRC Press, ISBN 0-8493-2463-7, Florida.

[45] Solum, M.S., Pugmire, R.J., Jagtoyen, M. \& Derbyshire, F. (1995). Evolution of carbon structure in chemically activated wood. Carbon, Vol. 33, No. 9, (1995), pp. 1247-1254, ISSN 0008-6223.

[46] Somorjai, G.A. (1994). Introduction to Surface Chemistry and Catalysis, Wiley Interscience, ISBN 0471031925, UK.

[47] Stoeckli, H.F, Kraehenbuehl, F., \& Morel, D. (1983). The adsorption of water by active carbons, in relation to the enthalpy of immersion. Carbon, Vol. 21, No. 6, (1983), pp. (589-591), ISSN 0008-6223.

[48] Valente-Nabais, J.M., \& Carrott, P.J.M. (2006). Chemical Characterization of Activated Carbon Fibers and Activated Carbons. Journal of Chemical Education, Vol. 83, No. 3, (March 2006), pp. (436-438), ISSN 0021-9584.

[49] Washburn, E.W. (1921). The Dynamics of Capillary Flow. Physical Reviews, vol. 17, (1921), pp. (273-283).

[50] Yates, M. (2003). Área superficial, textura y distribución porosa. In: Técnicas de análisis y caracterización de materiales. Faraldos, M., \& Goberna, C. (Eds.). pp. (221-246), CSIC, ISBN 84-00-08093-9.

[51] Zou, L., Huang, B., Huang, Y., Huang, Q., \& Wang, Chang'an (2003). An investigation of heterogeneity of the degree of graphitization in carbon-carbon composites. Materials Chemistry and Physics, vol. 82, No.3, (December 2003), pp. (654-662), ISSN 0254-0584. 


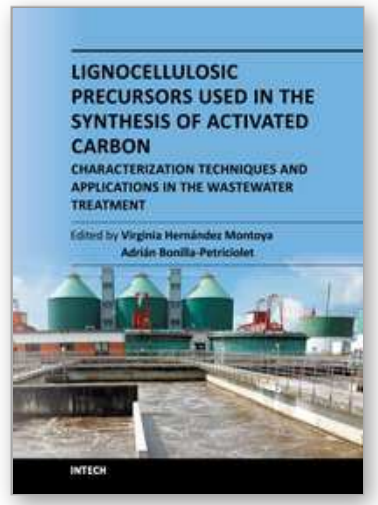

\author{
Lignocellulosic Precursors Used in the Synthesis of Activated \\ Carbon - Characterization Techniques and Applications in the \\ Wastewater Treatment \\ Edited by Dr. Virginia Hernández Montoya
}

ISBN 978-953-51-0197-0

Hard cover, 92 pages

Publisher InTech

Published online 29, February, 2012

Published in print edition February, 2012

The present book discusses the principal lignocellulosic precursors used in the elaboration of activated carbons in different countries such as Asia, America, Europe and Africa; the different methods and experimental conditions employed in the synthesis of activated carbons, including one analysis of the principal stages of the preparation such as carbonization and activation (i.e., chemical or physical activation). Also, the recent and more specialized techniques used in the characterization of activated carbons are discussed in this book. For example, the techniques employed to determine textural parameters (mercury porosimetry and gas adsorption isotherms at $77 \mathrm{~K}$ ) and different spectroscopies to determine chemical functionality (Raman, FT-IR, etc.) and other X-Ray techniques. Additionally, an overview of the application of activated carbons obtained from lignocellulosic precursors for wastewater treatment. Specifically, the analysis and discussion are focused on the advantages and capabilities of activated carbons for the removal of relevant toxic compounds and pollutants from water such as heavy metals, dyes, phenol, etc. Finally, the use of pyrolysis method for the valorization of two Mexican typical agricultural wastes (orange peel and pecan nut shell) for energy and carbon production is considered in this book.

\title{
How to reference
}

In order to correctly reference this scholarly work, feel free to copy and paste the following:

Carlos J. Durán-Valle (2012). Techniques Employed in the Physicochemical Characterization of Activated Carbons, Lignocellulosic Precursors Used in the Synthesis of Activated Carbon - Characterization Techniques and Applications in the Wastewater Treatment, Dr. Virginia Hernández Montoya (Ed.), ISBN: 978-953-510197-0, InTech, Available from: http://www.intechopen.com/books/lignocellulosic-precursors-used-in-thesynthesis-of-activated-carbon-characterization-techniques-and-applications-in-the-wastewater-treatment/notitle-specified-2

\section{INTECH}

open science | open minds

\author{
InTech Europe \\ University Campus STeP Ri \\ Slavka Krautzeka 83/A \\ 51000 Rijeka, Croatia \\ Phone: +385 (51) 770447 \\ Fax: +385 (51) 686166
}

\author{
InTech China \\ Unit 405, Office Block, Hotel Equatorial Shanghai \\ No.65, Yan An Road (West), Shanghai, 200040, China \\ 中国上海市延安西路65号上海国际贵都大饭店办公楼 405 单元 \\ Phone: +86-21-62489820 \\ Fax: +86-21-62489821
}


www.intechopen.com 
(C) 2012 The Author(s). Licensee IntechOpen. This is an open access article distributed under the terms of the Creative Commons Attribution 3.0 License, which permits unrestricted use, distribution, and reproduction in any medium, provided the original work is properly cited. 